\title{
Fenomenología
}

\section{Pride (orgullo)}

Carmen Chamizo Vega

Doctora por la Universidad de Alicante en el programa "Enfermería y Cultura de los Cuidados".

"Enfermera.Responsable de formacion de enfermeras residentes de enfermería familiar y comunitaria (EFyC) en la Unidad Docente Multeprofesional de Atención Familiar y Comunitaria del Principado de Asturias

Cómo citar este artículo en edición digital: Chamizo, C. (2015). Pride (orgullo). Cultura de los Cuidados

(Edición digital) 19, 41. Disponible en: http://dx.doi.org/10.14198/cuid.2015.41.02>

Correspondencia: Unidad Docente Multeprofesional de Atención Familiar y Comunitaria del Principado de Asturias. web:http://udocente.sespa.princast.es

Correo electrónico: carmenchamizo@hotmail.com

Recibido: 13/12//2014; Aceptado: 10/02/2015

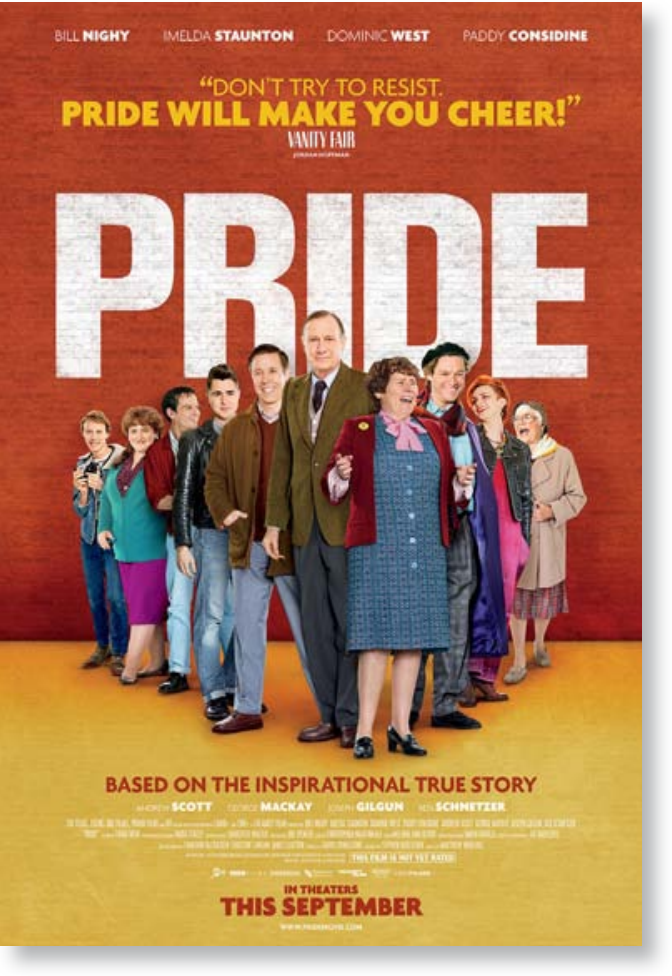

ABSTRACT

The thought caused by a simple fact, like a movie or a book revives feelings drowned. In this case, after seeing the film PRIDE, the author reflects on the need for tolerance and respect in society in general and nursing in particular, and emphasize the need to continue working with gender.

\section{RESUMO}

O pensamento causada por um fato simples, como um filme ou um livro revive os sentimentos se afogou. Neste caso, depois de ver o PRIDE filme, o autor reflete sobre a necessidade de tolerância e respeito na sociedade em geral e de enfermagem em particular, e enfatizam a necessidade de continuar a trabalhar com o gênero.

\section{RESUMEN}

El pensamiento provocado por un hecho sencillo, como una película o un libro, hace resurgir sentimientos ahogados. En este caso a raíz de ver la película PRIDE, la autora reflexiona sobre la necesidad de la tolerancia y el respeto en la sociedad en general y en la Enfermería en particular, así como recalcar la necesidad de seguir trabajando con perspectiva de género.

De cuando en cuando en nuestras vidas surgen momentos casuales que te impactan.

No son desgracias ni grandes regalos, son cosas sencillas como una frase en un libro, un olor, un paisaje, una conversación o una película. 
Ocurre el hecho y se desencadena una reacción de impacto que hace que todo lo que piensas se derrumbe, se tambalee y vuelva a encajar; como si la osa hibernando desde el invierno se despertara en primavera.

La certeza cómoda se traduce en un interrogante al instante y te sobresalta la incredulidad de no haber descubierto hasta entonces, lo que ahora ves claro.

Veo con estupor las caras sin máscaras y el grito de júbilo se transforma en un borbotón de ideas y palabras que convierto en un discurso escrito, para compartir el sencillo descubrimiento, que quizás sólo quien haya sentido lo mismo, puede comprender.

Esto me sucedió el otro día tras ir al cine a ver la película Pride (orgullo) del director Matthew Warchus y basada en un hecho real: el apoyo que un grupo de gays y lesbianas dieron a los habitantes de un pueblo de galés, durante la huelga de los mineros en 1984. Es una historia de solidaridad y de superación de prejuicios, que muestra el poder de la empatía, la tolerancia y de la generosidad.

No soy experta en cine por lo que, aunque me pareció una película deliciosa, obviaré la crítica cinematográfica y me centraré en la revelación que me produjo: comprendí que la solidaridad y la tolerancia son posibles en el mundo real y cercano; que la juventud de corazón y el coraje son dos elementos indispensables para ser reconocidos socialmente y no sólo los conocimientos y formas establecidas académicamente; que los derechos de cualquiera comienzan por lo más esencial, el respeto universal y el disfrute de la vida; que la endogamia no nos hará ser visibles; que el sufrimiento y la desgracia une; que la independencia supone desprenderse de ciertas mochilas sociales que portamos como naturales durante años; y un largo etcétera que dejo abierto.
Hace unos meses, en una comida de un tribunal de tesis se me insinuó que el "tema de género" ya estaba "pasado de moda", que ya no era necesario porque se luchaba por la Enfermería -en abstracto- y que el auge en tiempos pasados, estuvo relacionado con la abundancia de lesbianas en la profesión. Algo chilló en mi interior, se ahogó en mi garganta y lo tragué con un sorbo de buen vino, para que la alegría de la doctoranda no se viera apagada con la discusión. No obstante quedó dentro la impresión de tristeza, la cual se tornó en vómito escrito, al releer un artículo de Antonio Muñoz Molina ${ }^{1}$ sobre Virginia Wolf y su manera de escribir.

Con bellas palabras sobre VW, dice:

"Su prosa es una tentativa constante de crear un estilo que fluyera como el curso del tiempo, que atrapara la fugacidad y la velocidad de las cosas, la simultaneidad armónica de las palabras, los estados de conciencia, las sensaciones, los sentimientos: pero ese estilo tiene en el fondo la urgencia de una huida, la falta de sosiego de alguien que sabe que si baja la guardia o se queda inmóvil será atrapado por la bestia oscura que le viene a la zaga...., en ella hay un ansia peculiar, una inmediatez física, y además un coraje personal que los escritores varones no necesitan..., quiere lograr una forma fluida y abierta que contenga la vida sin falsificarla. Quiere la eliminación de los premioso o lo superfluo".

Como la Minería en la película PRIDE, quizás la Enfermería - en concreto - sería más visible si dejáramos a un lado los prejuicios enfermizos, el ansia de poder prepotente e incorporáramos la generosidad y la atención plena en lo sencillo y cercano. No me refiero al hacer sin parar, si no al ser auténtico y noble.

Como el grupo de $\mathrm{LGSM}^{2}$ de PRIDE (Les- 
bianas y Gays Sustentan a los Mineros), deberíamos estar orgullosas de que el grupo LGMSE (Lesbianas, Gays, Mineros Sustentan a las Enfermeras) fuera una realidad y el trabajo por la igualdad de género algo que no pasa de moda, que es necesario para toda la sociedad y que queda mucho que trabajar siendo la amplia meta de la igualdad de género, una meta social a la que la educación y las demás instituciones sociales deben contribuir ${ }^{3}$.

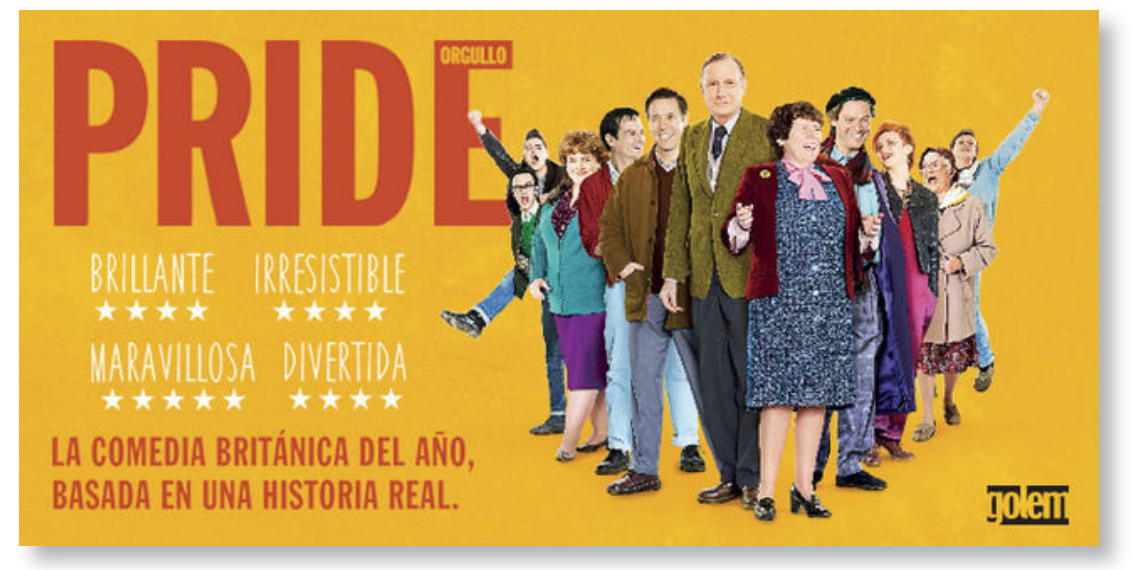

\footnotetext{
${ }^{1}$ Antonio Muñoz Molina. Diario incesante de Virginia Wolf. Diario El País 10022012 ${ }^{2}$ http://es.wikipedia.org/wiki/Lesbians_and_Gays_Support_the_Miners http://es.wikipedia.org/wiki/Lesbians_and_Gays_Support_the_Miners ${ }^{3} \mathrm{http}$ //www.unesco.org/new/es/education/themes/leading-the-international-agenda/education-for-sustainable-development/gender-equality/
} 